\title{
A Cardiac Calcified Amorphous Tumor Associated with End-stage Renal Disease: An Emerging Disease Concept
}

\author{
Hiroyuki Watanabe, Mai Shimbo and Hiroshi Ito
}

Key words: calcified amorphous tumor, mitral annular calcification, end-stage renal disease

(Intern Med 56: 2967-2968, 2017)

(DOI: 10.2169/internalmedicine.9348-17)

Cardiac calcified amorphous tumor (CAT) is a rare nonneoplastic cardiac mass composed of calcium deposits in a background of amorphous degenerating fibrin material. Recently, cardiac CAT has gained considerable attention. A MEDLINE search of studies published until April 2017 using the term "cardiac calcified amorphous tumor" resulted in 54 articles, 49 of which were reported in the last 10 years. Cardiac CATs were first described by Reynolds et al. in 1997 (1), who reported that they had come to recognize that cardiac CATs can arise in any of the four chambers. However, this situation has begun to change in recent years. Accumulating evidence suggests the presence of specific group of patients with end-stage renal disease (ESRD) in whom cardiac CAT arises from areas of mitral annular calcification (MAC) (2-6). In this issue of the Journal, Yoshimura et al. reported a case of MAC-related CAT in an ESRD patient on hemodialysis, and reviewed the reports of all patients with cardiac CAT (7). Of note, they ascertained that CAT at the mitral annulus is more frequent in patients with ESRD than in patients without ESRD. In contrast, the frequency of CAT in the right ventricle in patients without ESRD is higher than that in patients with ESRD. These clinical findings suggest a particular association between ESRD and MACrelated CAT formation, and supports the hypothesis that MAC-related CAT is etiologically different from CAT arising from other sites. Although the pathogenesis of cardiac CAT remains uncertain, this report by Yoshimura et al. may provide the first clues of the cause. At the very least, it seems likely that the dysfunctional calcium-phosphorus metabolism in ESRD has an impact on the formation of MACrelated CAT (8). Moreover, 21 of the 54 articles on cardiac CAT were reported from Japan. The predominance of cardiac CAT in Japanese patients is of interest as a racial characteristic.

Apart from cardiac CAT at other sites, MAC-related CAT represents a diagnostic challenge. The differential diagnosis includes vegetation, papillary fibroelastoma and thrombus. Although Magnetic Resonance Imaging (MRI) is usually helpful in the differential diagnosis of tumors-as it provides additional information on the tissue composition-MRI is of limited value in the diagnosis of MAC-related CAT. One possible reason for this is that MAC-related CAT is highly mobile and small in size. Conversely, the contribution of echocardiography in the characterization tissue is limited but it can evaluate rapid motion with ease. Thus, echocardiography is the diagnostic procedure of choice for assessing MAC-related CAT. The following aspects can be helpful in differentiating MAC-related CAT from vegetation (4): 1) continuity with the MAC, 2) a lack of association with the valve leaflets or regurgitation jet, and 3) revolving movement among the left atrial and ventricular cavities. Some recent reports have demonstrated that cardiac CAT has the potential to cause embolic events (9-11). Excision should thus be considered whenever a highly mobile CAT is found. Over the past 20 years, accumulating reports have significantly extended our knowledge regarding CATs. Nevertheless, our understanding of the pathology of cardiac CATs is still in the preliminary stages. Some questions remain unanswered. First, what is the relationship between MAC-related CAT and the liquefactive necrosis within the area of MAC (also known as annular caseous calcification)? Second, it is unclear whether an adequate intake of calcium-phosphorus can induce the regression of MAC-related CAT. In particular, the mechanisms underlying the formation of CAT represent an attractive target for future research on strategies to prevent the development of CAT.

The authors state that they have no Conflict of Interest (COI).

\section{References}

1. Reynolds C, Tazelaar HD, Edwards WD. Calcified amorphous tu- 
mor of the heart (cardiac CAT). Hum Pathol 28: 601-606, 1997.

2. Kubota H, Fujioka Y, Yoshino H, et al. Cardiac swinging calcified amorphous tumors in end-stage renal failure patients. Ann Thorac Surg 90: 1692-1694, 2010.

3. Kawata T, Konishi H, Amano A, et al. Wavering calcified amorphous tumour of the heart in a haemodialysis patient. Interact Cardiovasc Thorac Surg 16: 219-220, 2013.

4. Fujiwara M, Watanabe H, Iino $T$, et al. Two cases of calcified amorphous tumor mimicking mitral valve vegetation. Circulation 125: e432-e434, 2012.

5. Takeuchi T, Dohi K, Sato Y, et al. Calcified amorphous tumor of the heart in a hemodialysis patient. Echocardiography 33: 19261928, 2016.

6. Matsukuma S, Eishi K, Tanigawa K, et al. Swinging calcified amorphous tumors with related mitral annular calcification. Ann Thorac Surg 101: e103-e105, 2016.

7. Yoshimura S, Kawano H, Minami T, et al. Cardiac calcified amorphous tumors in a patient with hemodialysis for diabetic nephropathy. Intern Med 56: 3057-3060, 2017.
8. Tanaka A, Mizuno M, Suzuki Y, et al. Calcified amorphous tumor in the left atrium in a patient on long-term peritoneal dialysis. Intern Med 54: 481-485, 2015.

9. Nazli Y, Colak N, Atar IA, et al. Sudden unilateral vision loss arising from calcified amorphous tumor of the left ventricle. Tex Heart Inst J 40: 453-458, 2013.

10. Suh JH, Kwon JB, Park K, et al. Calcified amorphous tumor in left atrium presenting with cerebral infarction. J Thorac Dis 6: 1311-1314, 2014.

11. Singu $T$, Inatomi $Y$, Yonehara $T$, Ando $Y$. Calcified amorphous tumor causing shower embolism to the brain: a case report with serial echocardiographic and neuroradiologic images and a review of the literature. J Stroke Cerebrovasc Dis 26: e85-e89, 2017.

The Internal Medicine is an Open Access article distributed under the Creative Commons Attribution-NonCommercial-NoDerivatives 4.0 International License. To view the details of this license, please visit (https://creativecommons.org/licenses/ by-nc-nd/4.0/).

(C) 2017 The Japanese Society of Internal Medicine

Intern Med 56: 2967-2968, 2017 